\title{
PREVENÇÃO DE STRESS OCUPACIONAL EM LINHA DE MONTAGEM: UM ESTUDO DE CASO MEXICANO*
}

Miguel Matrajt

Professor e Profissional de Saúde Mental da Universidad Autónoma del Estado de Morelos, México.

Traduçāo de Genl Goldschmidt, revista por Edlth Seligmann Silva.

* RESUMO: Este estudo de caso apresenta a aplicação de uma metodologia, que inclui a análise ergonômica, a análise institucional, dinâmica de grupo e entrevistas individuais, em uma fábrica no México. O problema que provocou o estudo foi a queda de produtividade, relacionada pela direção da empresa com a existência de stress ocupacional. Utilizando-se da abordagem da pesquisa-ação, o estudo focalizou o pessoal de nível administrativo e de linha de montagem nos quais se podia observar sinais de stress. Foram identificadas as causas do problema e, com a participação dos envolvidos, foi estabelecido um programa de prevenção de stress ocupacional. Resultados positivos foram observados após a implementação do programa.

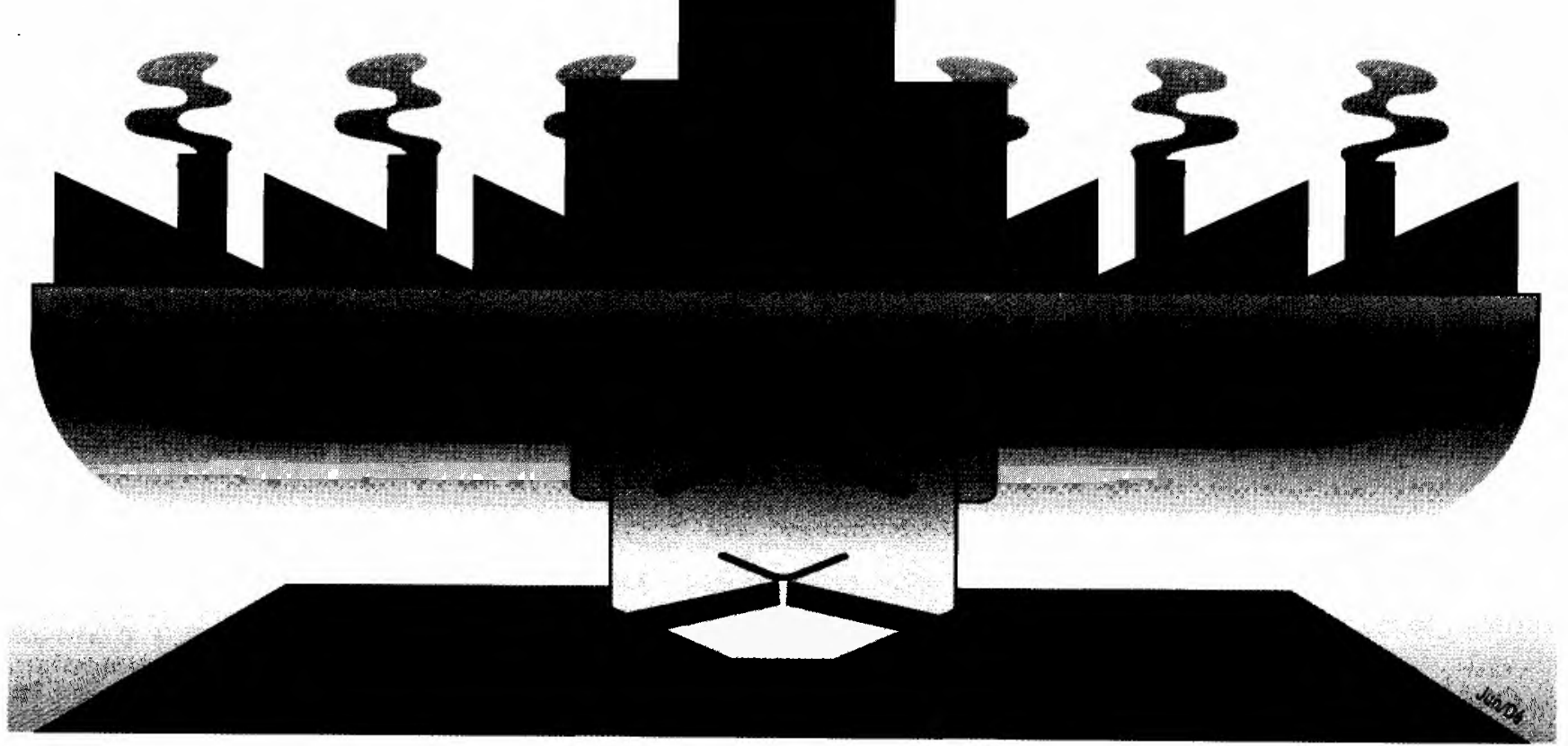

* PALAVRAS-CHAVE: Saúde mental ocupacional, saúde mental, stress ocupacional, análise ergonômica, produtividade, canais de comunicação.

* ABSTRACT: This case study presents a methodology including the use of ergonomic analysis, institutional analysis, group dynamics and interviews. It was applied to a manufacturing company in Mexico, which presented decline in productivity due to work-related stress. It is used the research-action approach, the study dealt with managers and assembly-line workers showing signs of stress. The causes of the problem were identified and a stress prevention programme was set. Positive results were reported following the programme implementation.

* KEY WORDS: Occupational mental health, mental health, work-related stress, ergonomic analysis, productivity, channels of communication. 


\section{CONTEXTO}

Vários executivos de alto nível de uma companhia manufatureira multinacional de alta tecnologia (companhia Z) conheceram o autor deste trabalho num encontro sobre saúde ocupacional. Depois disso, esses executivos convidaram o autor (que é especialista em saúde mental relacionada com o trabalho) para uma reunião na companhia para discutir a solução de problemas humanos da empresa.

$\mathrm{O}$ autor conversou com nove executivos da companhia (dois vice-presidentes e sete diretores), que descreveram os problemas que tinham identificado: um clima geral de profundo descontentamento em praticamente todos os setores da empresa; um declínio da produtividade, que era substancialmente maior no nível administrativo; e uma incidência de problemas psicossomáticos que indicava claramente a existência de stress. Estes problemas tinham sido identificados ao longo de um período de dois anos. A empresa

As duas convicções eram infundadas, mas, mesmo

assim, eram consideradas

como verdades absolutas e as pessoas envolvidas agiam em função delas. Isto pode ser denominado de produto da “imaginação institucional”. tinha tentado resolvê-los usando seus próprios recursos e agindo em duas frentes principais: modificando os programas de trabalho e fazendo com que os departamentos de psicologia e de relações públicas tomassem algumas medidas (informações, organização de atividades etc.). Depois de verem essas medidas fracassarem, resolveram recorrer à ajuda externa.

O autor propôs um estudo-piloto nos seguintes moldes:

- o primeiro dia seria usado para identificar como o trabalho em geral era organizado e as características da empresa como instituição;

- o segundo dia consistiria em duas reuniões de grupo (cada uma com duas horas de duração) e quatro entrevistas individuais com pessoas do nível administrativo escolhidas aleatoriamente.

- o terceiro dia seria dedicado à repetição das atividades dos dois dias anteriores, mas, desta vez, com operários da linha de montagem.

Além desta atividade-piloto, o autor elaborou um relatório escrito contendo observações preliminares ("diagnóstico provisório da situação") e uma proposta de continuação do trabalho, estabelecendo objetivos, prazos e custo.

\section{VERIFICAÇõES PRELIMINARES}

A companhia $Z$ tem duas fábricas localizadas em dois estados da República do México, além da sede da empresa, possui mais de 4.000 empregados e é organizada da mesma maneira que a 
matriz internacional e as filiais em outros países. A estrutura organizacional da empresa é decidida a nível central, com a participação dos executivos do mais alto escalão de cada filial. A companhia já existe há décadas e, em geral, tem se expandido constantemente. Muitos executivos passam por várias filiais e matrizes da companhia durante suas carreiras profissionais e, portanto, possuem um conhecimento profundo do modo de operação da companhia como um todo.

Quanto aos métodos administrativos, existem dois canais de comunicação: o canal formal, que respeita a estrutura organizacional da companhia, e o canal informal que consiste de rumores, fofocas, estórias ouvidas em bares etc. No entanto, as informações recebidas através destes dois canais muitas vezes são contraditórias e o maior peso é dado ao canal informal. Da mesma forma, existem dois conjuntos de padrões e de sistemas de valores, o que origina conflitos para muitas tomadas de decisão, determinando também algumas das exigências mais stressantes. Verificou-se que problemas pessoais nas relações entre executivos criavam problemas no ambiente de trabalho. Por exemplo, a rivalidade entre dois executivos se reflete nas ações de seus respectivos subordinados. Isto, por sua vez, causa um impacto negativo sobre os níveis de cooperação necessária entre departamentos. Um resultado significativo da diminuição da cooperação entre departamentos é o aumento do tempo necessário para se realizar as operações. Isto aumenta a sobrecarga física e mental e também os conflitos familiares.

No estágio preliminar, surgiram dois fatos particularmente interessantes no nível dos operários da linha de montagem. O programa de produção era extremamente rígido, com ritmos que variavam substancialmente sem razão aparente, e existia uma extrema ambivalência nas relações entre colegas, claramente originada no sistema de prêmios.

\section{População alvo}

A população alvo do programa de prevenção do stress consistiu de 130 executivos e 3.600 operários da linha de montagem da companhia Z.

\section{Abordagem e intervenção \\ A abordagem proposta foi do tipo pesquisa-ação. Os objetivos da ação proposta foram os seguintes:}

1. compreender melhor as causas do stress constatado durante a primeira fase e investigar outros fatores que requerem análise mais aprofundada. Isto é chamado de "diagnóstico da situação" (Fase A);

2. procurar, por meio da participação de especialistas, executivos e operários da linha de montagem, eliminar e/ou modificar as causas de stress. Isto é chamado de "fase corretiva" (Fase B);

Estes planos seriam realizados num prazo de 17 semanas. Três semanas foram destinadas à preparação da Fase $\mathrm{A}$, seis semanas para sua implementação, quatro semanas para analisar as conclusões tiradas da Fase A e preparar a Fase B, e quatro semanas para implementar a Fase B. Um segundo período de doze meses incluía a supervisão subseqüente, ajustamento e acompanhamento 
dos resultados. Foram indicados quatro critérios de avaliação das vantagens de se realizar o programa proposto, em termos de custo-benefício:

a. uma vez que o nível de produtividade geral da companhia era, em média, $7 \%$ mais baixo do que o de outras filiais da companhia (isto era atribuído ao stress ocupacional), seria suficiente diminuir esse número em apenas um ponto percentual. A diminuição de $1 \%$ seria mais do que suficiente para cobrir investimento feito no estudo c no programa de ação;

b. da mesma forma, a diminuição de $12 \%$ nos problemas psicossomáticos dos executivos, embora suas despesas médicas fossem cobertas por um seguro saúde, geraria economias em termos de horas de trabalho perdidas e de custos de treinar executivos substitutos. Estas economias justificariam o investimento no estudo;

c. alćm disso, a diminuição de $22 \%$ nos problemas psicossomáticos e nas faltas injustificadas ao trabalho pelos operários da linha de montagem, que também tinham cobertura para assistência médica e auxílio doença, compensaria o investimento feito no estudo e no programa de ação;

d. além destes critérios de avaliação quantitativa, haveria benefícios qualitativos, resultantes da melhoria das relações interpessoais e de uma diminuição dos problemas interpessoais.

\section{OPROCESSOOEPESOUISA-ACAO}

\section{FASE DRWWOSTICO DA SIUAGAO}

\section{Estudo da instituição}

Usando a metodologia da psicologia institucional ${ }^{1}$, foram examinadas as características da companhia, como liderança, valores e padrões explícitos e implícitos, canais de comunicação formais e informais, o sentimento de identificação dos trabalhadores com a empresa, o grau de receptividade às queixas e sugestões, a rigidez da empresa e/ou sua propensão à mudança, origem e possibilidades de mudança etc. Estas informações foram coletadas por meio de observações diretas, análise das normas e entrevistas. Foram tiradas as seguintes conclusões:

a. o canal de comunicação informal (constituído basicamente de rumores, fofocas e estórias ouvidas no bar) era uma importante fonte de stress no ambiente de trabalho. A nível administrativo, fonte e transmissores básicos deste canal eram as secretárias dos executivos. Era impossível verificar as informações passadas por este canal ou refutar informações falsas. Este canal informal de comunicação era, portanto, freqüentemente usado com o propósito específico de espalhar informações falsas sobre as pessoas;
1. BAREMBLITT, G. El inconciente institucional. Mexico city: Nuevomar, 1981; GUATTARI, F. La intervención institucional. Mexico city: Folios Ediciones, 1981; LOURAU. R. Anàlisis institucional y socioanàlises. Mexico city: Editorial Nueva Imagen, 1977; SAIDÓND, 0.; KONONNOVICH, B. La escena institucional. Buenos Aires: Lugar Editorial, 1991; PICHÓN RIVIERI, E. Teoria del vinculo. Buenos Aires: Nueva Visión, 1977. 
b. em conseqüencia de informações fornecidas através do canal informal de comunicação, os executivos de nível superior estavam convencidos de que o presidente da filial em breve iria se aposentar, muito antes da data devida. Também estavam convencidos de que seu substituto seria um dos executivos da filial. As duas convicções eram infundadas, mas, mesmo assim, eram consideradas como verdades absolutas e as pessoas envolvidas agiam em função delas. Isto pode ser denominado de produto da "imaginação institucional" ${ }^{2}$ Com base nesse produto da imaginação institucional, o pessoal de nível administrativo se lançou numa

A conclusão mais importante foi que o aumento da jornada de trabalho tinha elevado o esforço físico, intelectual e psiquico além de níveis recomendáveis. Isso resultou em mais erros, aumento no nivel geral de stress e um exagerado sentimento de fadiga $e$ descontentamento generalizado. competição vclada, que nunca era discutida explicitamente. Esta situação resultou num desejo compulsivo de mostrar competência no trabalho e numa perda da confiança e coopcração mútuas. Esta era outra importante causa do ambiente de trabalho stressante;

c. além de tudo isso, havia na companhia $Z$ uma tradição de procurar um bode expiatório para levar a culpa do que acontecia. A vítima era obrigada a deixar a empresa, mesmo que a solução do problema envolvesse uma área mais ampla do que aquela pela qual o suposto culpado era responsável. Este era outro importante fator de stress que dava a todos um incentivo para mostrar capacidade gerencial, mesmo quando não era o caso. O problema acima teve o efeito de exacerbar os conflitos interpessoais, que começaram a escapar ao controlc e a criar um ambiente de trabalho negativo;

d. estes fatores foram responsáveis pela queda da produtividade. Para compensar essa queda, mesmo contrariando seus próprios valores organizacionais, a empresa aumentou o horário de trabalho a nível administrativo. Esta prática foi adotada sem qualquer acordo formal sobre o aumento da jornada de trabalho. Nos seis meses que precederam este estudo, a média semanal de horas de trabalho em alguns setores tinha sido de 58 horas, contra 45 horas semanais do horário formal. Esta situação aumentou a carga física, mental e emocional das pessoas envolvidas. Criou também um ambiente stressante durante os períodos de descanso e intervalos de refeições. $O$ aumento da carga horária teve várias conseqüências para as relações dos executivos com seus familiares. O pior impacto foi sobre as famílias que vinham funcionando bem. Surgiram dois grupos. Um constituído dos executivos cujas famílias reagiram negativamente à situação e um segundo grupo incluindo aqueles que não tinham responsabilidades familiares. Os executivos do segundo grupo estavam numa situação melhor em comparação com os do primeiro gru-

2. VOLNOVICH, J. El espacio institucional. Buenos Aires: Lugar Editorial, 1991. 
po. Aqueles que já não tinham uma boa situação familiar ficaram, então, sujeitos a mais uma fonte de stress em conseqüência da jornada de trabalho mais longa;

e. o ambiente stressante no nível gerencial era transmitido por uma reaçāo em cadeia aos operários. No entanto, nem todos os setores sofreram igualmente com o aumento da jornada de trabalho. Para alguns isto até constituiu um incentivo interessante. $\mathrm{A}$ área onde as mudanças causaram mais impacto foi a linha de montagem. O exame do programa de trabalho da linha de montagem mostrou que ele era excessivamente rígido em alguns aspectos. Os programas de trabalho eram estabelecidos centralmente com a participação de executivos dos mais altos escalões de todas as filiais. No entanto, estes tinham sido influenciados pela cultura das matrizes da companhia. Os trabalhadores da linha de montagem respondem de acordo com sua cultura laboral de origem, e para esta existem graus de liberdade que se fazem absolutamente indispensáveis.

\section{Estudo ergonômico}

Usando os métodos convencionais, foram estudadas as características do trabalho, incluindo a organização do trabalho, as tarefas realizadas, os métodos usados na seleção de pessoal, o treinamento específico recebido pelos funcionários, as características específicas do trabalho realizado por cada seção, quem planejava o trabalho, o grau de participação dos operários no planejamento do trabalho e/ou mudanças feitas na organização do trabalho, horários, turnos, períodos de descanso, o ritmo do trabalho, a carga de trabalho em termos físicos, cognitivos (intelectuais) e psicoafetivos (psíquicos). Este estudo foi feito por meio de observações diretas, análise das normas da organização do trabalho na companhia, entrevistas etc. ${ }^{3}$

Finalmente, foram comparados os dados pesquisados e testados a nível internacional com os dados obtidos na fábrica. A conclusão mais importante foi que o aumento da jornada de trabalho tinha elevado o esforço físico, intelectual e psíquico além de níveis recomendáveis. Isso resultou em mais erros, aumento no nível geral de stress e um exagerado sentimento de fadiga e descontentamento generalizado. Os autores acreditam que este era a mais importante causa do absenteísmo injustificado. Além disso, certos aspectos do modo como o trabalho era planejado eram desnecessariamente rígidos em termos de realização de tarefas e de produção. Isto incluía a maneira de dar intervalos individuais (como por exemplo, para ir ao banheiro) e coletivos, o tempo destinado ao trabalho de infra-estrutura (como conserto e limpeza de equipamentos), regras quanto à maneira de realizar tarefas relacionadas com o trabalho e a necessidade de autorização para diálogo e trocas verbais.

\section{Estudo de grupo}

Foi feito um estudo dos grupos de trabalho estabelecidos (departamentos, seções etc.) usando a metodologia de dinâmi-
3. FREYSSENET, M.; HIRATA, H. Mudanças tecnológicas e participação dos trabalhadores: os círculos de controle de qualidade no Japão. Revista de $A d-$ ministração de Empresas, v. 25 , n. 3, 1985: GUELAUD, F. et alii. Para un anàlisis de las condiciones del trabajo obrero en la empresa. Mexico: INET, 1981; TEIGER, C. Lo que pasa en las sesiones de formación de trabajadores. Plaisir et souffrance dans le travail. Paris: OACIP, 1988. Fadigue ou équilibre par le travail. Paris: Entreprise Moderne d'Edition, 1980; CORIAT, B. El taller y el cronómetro: Ensayo sobre el Taylorismo, el Fordismo y la producción en masa. Mexico city: Siglo XXI, 1985; LIBOUBAN, C. Un aspecto nuevo de la carga de trabajo: la carga psíquica. In: DEJOURS, C et alii. Psycopathologie du travail. Paris: Entreprise Moderne d'Edition, 1985. 
ca de grupo. O estudo se baseou em duas reuniões de três horas com cada grupo e se concentrou nos papéis, relações, canais de comunicação, imagem de grupo etc., cobrindo um total de 20 grupos. $^{4}$

Embora os resultados diferissem substancialmente entre os niveis administrativo e de linha de montagem, em ambos os casos foram encontrados fatores altamente stressantes.

No nível administrativo, a dinâmica do grupo foi fundamentalmente determinada pelas qualidades pessoais de liderança dos chefes dos grupos. Por exemplo, se os chefes de grupo não davam importância a relações familiares, eles exigiam trabalho e reuniões fora do horário regular de trabalho. Em muitos casos era exercida uma pressão psicológica inconsciente, uma vez que aceitar

Estabelece-se uma sinergia

entre o estímulo econômico e a

pressão psicológica de não

querer parecer culpado aos

olhos dos pares e amigos pela

perda do prêmio. ou rejeitar as regras do jogo ditadas pelo chefe era interpretado como lealdade, solidariedade, amizade, afeição etc., ou como indiferença, traição ou conspiração em favor de um rival. Embora em termos formais a aceitação de trabalho e de horas adicionais fosse voluntária, os padrões implícitos da instituição endossavam os métodos de trabalho do chefe. Aqueles que não cooperavam com os padrões implícitos da companhia não tinham nenhuma oportunidade na carreira. Alguns chefes, conforme suas características pessoais, tendiam a transferir para os subordinados a pressāo que recebiam de seus superiores. Isto efetivamente transferia seu stress para os outros. Já aqueles chefes com tendências paternalistas, absorviam todo o impacto do stress e se comportavam como protetores. Outros viam no sucesso de seus departamentos um fator fundamental de seu próprio senso de bem-estar e auto-estima, o que implicava uma exigência de perfeccionismo. Outros ainda davam mais peso à responsabilidade coletiva e à criatividade.

A dinâmica de grupo também era afetada por dois aspectos muito peculiares de inúmeras culturas latino-americanas, ou seja, a importância de ligações afetivas (para fins de promoção e de gratificações, estas são muito mais importantes do que conhecimento e/ou desempenho no trabalho) e uma forma de comunicação em que o silêncio, subentendidos e inverdades desempenham um papel fundamental. A interação entre todos os fatores acima resultou em grupos cujos níveis de stress relacionado com o trabalho variavam muito.

Entre os operários da linha de montagem verificou-se que os prêmios eram a principal causa de stress. Como se sabe, em muitas companhias os operários recebem um salário básico e uma série de prêmios que aumentam substancialmente sua renda. Estes prêmios, que são pagos para toda a seção ou todo o turno, formam a parte mais significativa da remuneração. Desse modo, cada operário se sente sob maior pressão por parte de seus colegas do que por parte de seu superior imediato ou da companhia. Psicologicamente, isto estabelece uma relação extremamente ambivalente entre colegas. Em outras
4. PICHÓN RIVIERI, E. Del psicoanàlisis a psicologia social. Buenos Aires: Nueva Visión 1977; BAREMBLITT, G. Grupos, teoria y tecnica. Rio de Janeiro: IBRAPSI, 1982: BAULEO, A. Contrainstituición y grupos. Madrid: Editorial Fundamentos, 1977: GUATTARI, F. Psicoanàlisis y transversalidad. Mexico city: Siglo Veintiuno Editores, 1976. 
palavras, estabelece-se uma sinergia entre o estímulo econômico (deve-se ressaltar que o mercado de trabalho mexicano é afetado pelo desemprego crônico e por baixos salários para o trabalho não qualificado) e a pressão psicológica de não querer parecer culpado aos olhos dos pares e amigos pela perda do prêmio.

\section{Exame de casos individuais}

Vários empregados do nível administrativo e da linha de montagem, escolhidos aleatoriamente, foram estudados através de entrevistas individuais e de algumas figuras de teste de projeção (TAT). Este trabalho abrangeu 183 pesssoas. Cada pessoa passou por dois encontros de uma hora ou de uma hora e meia. ${ }^{5}$

Esta análise mostrou que os empregados da companhia $\mathrm{Z}$ têm as características específicas de serem muito competitivos, muito individualistas, darem muita importância ao sucesso, aos bens de consumo e ao ambiente cultural moderno. Tudo isso pode ser alcançado desde que os empregados permaneçam na companhia e lá façam carreira. Portanto, para todos os empregados, independentemente do seu nível na hierarquia, permanecer na companhia tem prioridade sobre muitos outros objetivos. No caso de alguns executivos, isto tem prioridade sobre qualquer outro objetivo.

Os empregados que sofriam de doenças psicossomáticas se caracterizavam por uma grande tendência a negar os conflitos interpessoais. No caso de muitos deles, suas histórias de vida evidenciavam que seu lado agressivo e suas depressões geravam mais incômodo do que o normal. Também demonstraram uma relação inversa entre seu potencial de expressão interpessoal e suas manifestações de doenças psicossomáticas. Em muitos casos, a pressão do tempo (ter que terminar uma tarefa num prazo curto estabelecido por outros) era reconhecida como altamente stressante. Outros fatores de stress expressos eram a. todos os conflitos de amor-ódio, mesmo nos mais altos níveis; $\mathbf{b}$. a aprovação do grupo (colegas, familia etc.); c. qualquer situação que desse origem a culpa; $\mathrm{c}$ d. situações de separação.

No total, esta fase cobriu um pouco mais de 400 pessoas (10\% dos empregados da companhia). Uma vez elaborado o diagnóstico provisório da situação, ficou decidido que não havia necessidade de exames médicos ou avaliações neurológicas. Os indicadores de stress relacionado com o trabalho contidos na avaliação foram considerados suficientemente consistentes. Embora, no caso desta empresa, tivesse sido possível propor testes de laboratório para se obter informações médicas, nossa intenção era testar um modelo de ação que fosse o mais econômico possível, que pudesse ser amplamente aplicado nos países em desenvolvimento.

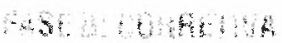

De posse das informações acumuladas que foram processadas ao longo de quatro semanas, a equipe de estudo realizou uma série de reuniões com grandes grupos (entre 30 e 100 pessoas)
5. MATRA.JT, M. Salud mentaly trabajo. Cuernavac: UAEM, 1986; ___ . Industrialización, processo de trabajo y salud mental. Subjetividad $y$ Cultura, n. 1, 1991; Estudios en salud mental ocupacional (a ser publicado). 
em seus ambientes de trabalho. Foram feitas duas ou três reuniões com cada grupo dentro de um prazo de quatro semanas. Foram realizadas aproximadamente 120 sessões de duas a três horas a fim de se abranger todos os empregados da companhia.

Em todos os casos, foram usados os seguintes procedimentos para tentar reduzir a tensão no local de trabalho:

foi feita uma breve descriçāo das conclusões dos pesquisadores quanto às causas de stress na sessão ou grupo de trabalho;

os funcionários eram encorajados a discutir, desenvolver ou rejeitar as idéias apresentadas pelos pesquisadores, que continuavam a aumentar as informações que haviam dado no início. O propósito básico da equipe era que os funcionários confirmassem a hipótese que tinha sido formulada a partir de suas próprias experiências e que compartilhassem com a equipe o que pensavam e sentiam a respeito do trabalho e de sua organização (inclusive as causas de stress);

no fim da primeira sessão, os empregados eram convidados a propor mudanças que eliminassem as causas do stress. Nesse momento, o importante era que formulassem propostas que pudessem ser discutidas por todos na sessão seguinte. $O$ papel do pesquisador responsável pela coordenação de cada sessão era promover a participação de todos os empregados, garantir que todas as idéias apresentadas fossem levadas em conta, apontar as consequiências de cada proposta em termos psicológicos, grupal e instituicional e a necessidade de se levar em conta o nível de produtividade da companhia, procurar fazer com que as modificaçôes sugeridas fossem adotadas como uma proposta coletiva, que tinha que ser perfeitamente compreendida por todos, e transmitir o conhecimento e experiência dos pesquisadores, inclusive o que fora constatado em outros setores da mesma empresa, para que a proposta fosse o mais científica possível;

na sessão seguinte (ou sessões, se necessário), todas as propostas eram bem analisadas. Era proposto um plano para aquelas que recebessem maior consenso (deixando em aberto outras propostas que poderiam ser reexaminadas se as mais aceitas não funcionassem) e um método de autogestão era escolhido para implementar as mudanças.

Após essas sessões, diversas iniciativas e decisôes foram tomadas para superar as causas do stress.

\section{Plano para modificar as causas de stress}

ficou combinado que todos procurariam não acreditar em qualquer informação que circulasse através dos canais informais de comunicação. Além disto, todos iriam tentar mudar os canais formais de comunicação para que eles pudessem cumprir sua função e ser uma fonte confiável de informaçôes. Os funcionários do nível adminis- 
trativo procuraram não divulgar informações classificadas como duvidosas. Funcionários dos níveis apropriados tomaram as iniciativas de divulgar as informações necessárias para acabar com as fofocas institucionais que vinham sendo uma das principais causas de stress;

foi decidido analisar em profundidade o mecanismo de atribuição de culpa aos indivíduos por falhas e problemas que eram, na realidade, resultantes de decisões tomadas pela companhia;

foram sugeridos mecanismos para resolver os conflitos interpessoais ou, pelo menos, eliminar seu impacto sobre o trabalho em questão;

decidiu-se mudar o horário de trabalho para abolir a prática estabelecida de estender o tempo de trabalho e evitar interferência nos intervalos para descanso e refeiçōes;

decidiu-se modificar os critérios usados para mudar a velocidade da linha de montagem de modo que esta não fosse considerada como "solução" definitiva para outros problemas de produtividade da companhia como um todo;

foi feita uma análise minuciosa dos requisitos do programa de trabalho. A análise visava a fazer mudanças que estivessem de acordo com as tradições trabalhistas mexicanas, mas que não comprometessem a produtividade e a eficiência. Todos os empregados, supervisores e engenheiros participaram da análise. Com a participação destes grupos, foi analisado o esforço físico e mental necessário à realização do trabalho para que se pudesse avaliar os limites de tolerância e, conseqüentemente, as possibilidades reais de horas extras. Foram estabelecidos parâmetros experimentais para cada seção;

a nível administrativo, foi feita uma análise minuciosa das diferentes formas de liderança de grupo, procurando, na medida do possível, manter os estilos pessoais e, ao mesmo tempo, eliminando os aspectos causadores de stress para o resto do grupo. Por exemplo, julgou-se necessário reservar um tempo para se refletir regularmente, a nível de grupo (a cada dois ou três meses), para avaliar a organização do trabalho realizado pelo grupo como um todo;

todos os operários da linha de montagem participaram da análise do sistema de prêmio. Foi introduzida uma série de mudanças (diferentes para cada setor de produção) visando a diminuir a ambivalência das relações grupais e o nível de stress individual. Por exemplo, o critério de atribuição de prêmio por seção foi substituído por um sistema de desempenho geral médio (pontualidade geral, assiduidade geral etc.);

com base nas conclusões dos estudos de indivíduos e de grupos, foram sugeridas mudanças ao departamento de recruta- 
6. Item extraído do relatório originalmente formulado pelo autor. mento e seleçāo de pessoal. As mudanças sugeridas visavam a ajudar evitar que indivíduos com traços de personalidade vistos como fatores de risco fossem colocados em setores identificados pela equipe como muito stressantes. Além disto, a equipe sugeriu que em todos os niveis, mas principalmente no nível administrativo, fosse formalmente reservado um tempo para reuniões de grupos e discussões sobre a organização da empresa e as relações entre pares, chefes e seus subordinados. Estas "reuniōes" deveriam facilitar a compreensão mútua e a busca de alternativas e não se transformar em fóruns para confissão, acusação ou mera repetição dos desentendimentos da administração. A equipe também sugeriu a organização voluntária de esportes e atividades sociais fora do horário de trabalho.

Durante os doze meses que se seguiram à intervenção, houve uma diminuição de $17 \%$ nas doenças psicossomáticas, a nível administrativo, e de $15 \%$ entre os operários da linha de montagem. $\mathrm{O}$ autor acredita que é preciso distinguir entre o declínio no absenteísmo (que é o que interessa à empresa) e o declínio na incidência de doenças psicossomáticas (que é o que interessa aos especialistas em saúde mental ocupacional). Embora os dados fossem insuficientes para se estabelecer uma curva proporcional, a tendência geral foi de uma diminuição progressiva nos dois índices.

Também foi registrado um aumento progressivo do nível de produtividade da companhia, que foi atribuído à diminuição das situações de stress. No período de doze meses após o estudo, a produtividade diferencial em relação à média foi reduzida para $5.3 \%$ com uma tendência geral a melhorar. Estimou-se que nos próximos 18 meses a companhia alcançaria a média geral. $\mathrm{O}$ absenteísmo injustificado diminuiu e alcançou o nível médio das empresas em termos nacionais. O ambiente geral humano e do ramo de trabalho na companhia melhorou substancialmente.

Todos os critérios de avaliação que, de acordo com nosso modelo teórico, são indicadores de mudanças na situação de stress relacionado com trabalho, mostraram uma mudança significativa em termos positivos. Na análise final, o levantamento e a ação realizados tiveram um duplo benefício: corrigiram os efeitos do stress e evitaram novos desenvolvimentos e repercussões do mesmo.

A apresentação deste estudo de caso visa a abrir perspectivas para o desenvolvimento da metodologia, adequando-a às exigências de diferentes situações de trabalho. Assim, a proposta do autor é que se levem a cabo novos estudos e se determinem especificidades de acordo com ramo de atividade, região, cultura, tipo de ocupacão e de organizaçāo do trabalho.

A fundamentação obtida através de tais pesquisas permitirá que se construam esquemas e procedimentos de diagnóstico de intervenção preventiva participativa que operem de acordo com as peculiaridades de cada situação de trabalho. ${ }^{6}$ 